\title{
Effects of curing regimes and cement fineness on the compressive strength of ordinary Portland cement mortars
}

\author{
Fathollah Sajedi , Hashim Abdul Razak
}

The compressive strength of cement mortar and concrete plays a fundamental role in the design and construction of the concrete structures [1]. The objective of curing is to keep concrete saturated or as nearly wet to assist the hydration of cement

The rate and degree of hydration, and the resulting strength of concrete and other properties, depend on the curing process that follows placing and consolidation of the plastic concrete. Hydration of cement continues for years at a decreasing rate as long as the mixture contains water and the temperature conditions are favorable. Once the water is lost, hydration ceases. Curing of mortar and concrete is very essential for their strengths gain durability. Concrete is generally cured by water ponding [2]. In general, curing ensures that the mix water is available for cement hydration.

Curing is used to provide an appropriate environmental condition within a concrete structure, i.e. relative humidity and temperature to ensure the progress of hydration reactions causing the filling and segmentation of capillary voids by hydrated compounds. In a specific condition, curing duration to achieve an adequate hydration of Portland cement mortars and concretes depends mainly on the chemical and mineralogical compositions and also the fineness of cement. $\mathrm{ACl} 308$ recommended practice [3] suggests 7 days of moist curing for most structural concretes. However, the period of curing should be extended to 14 days when the cement contains supplementary cementitious materials, such as slag and fly ash, owing to the slow hydration reactions between supplementary cementitious materials and the calcium hydroxide. The process of this reaction requires the presence of water to produce the cementing compounds to contribute for filling the capillary voids.

According to Powers [4] a minimum of $80 \%$ humidity is required for hydration of cement. Moreover, he suggested that the permeability of the surface concrete may increase 5-10-folds if concrete is insufficiently cured. The most effective method of curing is to keep the exposed concrete surface continuously moist by ponding 
and spraying with water. In this method, the concrete kept fully saturated during the period, the ideal condition for strength development and hydration of cement.

If the potential of mortar and concrete with regards to strength and durability is to be fully realized, it is most essential that they be cured adequately. The curing becomes even more important if they contain supplementary cementing materials such as ggbfs, fly ash, and silica fume and are subjected to dry and hot environments immediately after casting [5]

The necessity for curing arises from the fact that hydration of cement can take place only in water-filled capillaries so in order to obtain a good mortar or concrete, the placing of an appropriate mix must be followed by curing in a suitable environment during the early stages of hardening and a loss of water by evaporation from capillaries must be prevented $[6,7]$.

Curing techniques and curing duration significantly affect the strength and other properties of mortar and concrete. The development of mortar properties such as strength depends on the hydration of cement. After placement, the only factors that influence cement hydration of a particular mortar are the availability of moisture and temperature. Proper curing can maintain a satisfactory moisture content and temperature in mortar and concrete during their early ages so that the desired properties may develop $[8,9]$.

One of the major determinants of cement quality is its fineness. It is well known that the compressive strength of cement increases with fineness, and that cement with a narrow size distribution has higher strength than those with a wide one. In this sight, grinding of cement, especially blended cements, has attracted interests of many researchers [10].

The most important property of cement is setting strength in concrete, and cement quality is assessed and controlled by measuring its strength under standard conditions. It is well known that the compressive strength of cement increases with fineness or specific surface area, and that for equal surface area, cements with a narrow particle size distribution have a higher strength than those with a wide size distribution. The chemical composition of the cement is a major determinant of its setting strength. In the cement industry, the fineness of the cement is usually expressed not as a size distribution but by surface area [11].

The hydration reactions in Portland cement is essential to improve the potential strength and durability of mortars and concretes.

This contribution depends on the type and fineness of 
cement, the type and the amount of supplementary material present, the water/cement ratio and the curing conditions, especially at early ages [12].

This paper reports the results of an investigation about ordinary Portland cement mortars studied after six curing regimes. These included moist (water) curing (wc) as control, curing at room temperature (ac), curing at water bath heated $(\mathrm{WH})$, curing at oven heated $(\mathrm{OH})$, curing at room temperature for first week after casting and after that in the water up to 90 days (aw/c), and curing in water for first week after casting and after that at room temperature up to 90 days (wa/c). Six groups of mortars; OM air and water cured (first group), OM-WH air and water cured (second group), OM-G6 air and water cured (third group), OM-aw and OM-wa cured (fourth group), $\mathrm{OM}-\mathrm{OH}$ air and water cured (fifth group), and OM-G6/WH air and water cured (sixth group) also were used. The objective of this study is to examine the compressive strength of ordinary Portland cement mortars under different curing regimes and cement fineness used in the investigation and also comparing the results obtained and determining the best and worst mixes for curing regime used.

2. Mix proportions, curing, and testing

Table 1 represents the mix proportions for different mixes. In all mixes W/ $B=0.33, S / B=2.25$ and silica sands were used. At first, based on particle size analysis (PSA), five grades of silica sands were mixed. Two minutes after that, cement was put into the mixture, followed by 2 min of mixing. Firstly, the mixing water was added to the mix and mixing was continued for 2 extra min, after which the required amount of super plasticizer was added. Mixing was continued for $2 \mathrm{~min}$ before finally, filling the moulds with two layers of fresh mortar and compacts each layer with ten impacts, by a rod of $16 \mathrm{~mm}$ diameter. Twenty-four hours after casting, the specimens were demoulded and cured in air under room temperature with $27 \pm 3$ _C and $65 \pm 18 \%$ relative humidity or in water $23 \pm 2 \_$C with time needed for breaking the specimens

\subsection{Materials}

The properties of the materials that have been used in the study are described as follows.

2.1.1. Cement

The cement used in all mixes was ordinary Portland cement (OPC). ASTM C10999 was used for determination of the compressive strength of hydraulic cement mortars, by use of $50 \mathrm{~mm}$ side cubes specimens. The specific gravity of cement used is about 3.14. Based on the PSA tests, the specific surface area (SSA) for OPC in use was determined to be $1.8939 \mathrm{~m} / \mathrm{g}$ and $3.0987 \mathrm{~m} / \mathrm{g}$ for grounded OPC in duration of $6 \mathrm{~h}$. The PSA diagrams for the cement used in the study are shown in Fig. 1. The chemical compositions of OPC used in this research have been determined by Xray fluorescence (XRF). Chemical properties of the cement are given in Table 2. 
Full text available at :

http://www.sciencedirect.com/science/article/pii/S0950061810005738

http://ac.els-cdn.com/S0950061810005738/1-s2.0-S0950061810005738-main.pdf? tid=09f98766-7820-11e39d0a-00000aacb35f\&acdnat $=1389156655$ 7805547d3ec55afc3716f2e77b5b146c 